\title{
Das Übereinkommen der Vereinten Nationen über die Verwendung elektronischer Mitteilungen bei internationalen Verträgen
}

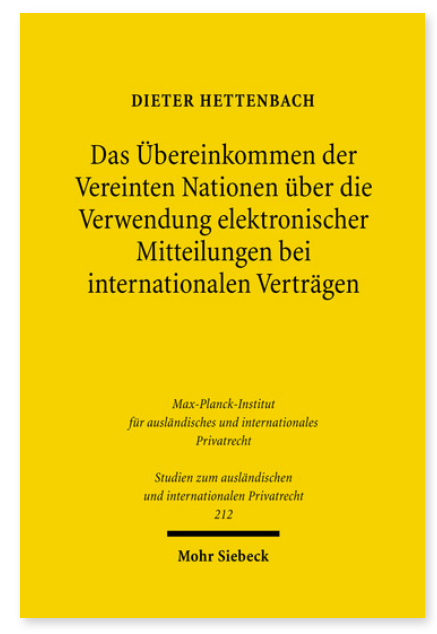

2008. XXIX, 334 Seiten. StudIPR 212

ISBN 978-3-16-151397-8

DOI 10.1628/978-3-16-151397-8

eBook PDF 89,00€

ISBN 978-3-16-149804-6

fadengeheftete Broschur 89,00€
Das UN-Übereinkommen über die Verwendung elektronischer Kommunikationsmittel bei internationalen Verträgen des UNAusschusses für internationales Handelsrecht UNCITRAL verfolgt das Ziel, allgemeine vertragsrechtliche Fragen des grenzüberschreitenden Gebrauchs elektronischer Kommunikationsmittel zu einer international einheitlichen Antwort zu führen.

Dabei befasst es sich vor allem mit dem Zeitpunkt und dem Ort der Abgabe elektronischer Erklärungen, zum Beispiel von EMails, und mit der Erfüllung von Formvorschriften auf elektronischem Wege. Außerdem setzt es sich mit der Abgrenzung zwischen Angeboten und unverbindlichen Erklärungen im Internet auseinander, regelt den Gebrauch von automatischen Nachrichtensystemen und Fehlerkorrekturmechanismen und geht auf Informationspflichten ein.

Dieter Hettenbach stellt den Anwendungsbereich und die einzelnen Bestimmungen des neuen Übereinkommens ausführlich und unter Darstellung ihrer Entstehungsgeschichte sowie ihres Zwecks vor. Zudem vergleicht er die inhaltlichen Regelungen des neuen Übereinkommens mit dem geltenden deutschen, europäischen und amerikanischen Recht.

Abschließend bewertet er die Vor- und Nachteile des Übereinkommens aus deutscher, europäischer und internationaler Sicht. Dabei stellt er sowohl einerseits die Bedeutung des Übereinkommens für andere Instrumente der

Rechtsvereinheitlichung - insbesondere das UN-Kaufrecht - als auch andererseits den begrenzten Regelungsbereich der neuen Konvention dar.

Dieter Hettenbach Geboren 1981; Studium der Rechtswissenschaft und des Europäischen Rechts in Würzburg; 2007 Promotion; seither Rechtsreferendar im Landgerichtsbezirk Frankfurt a.M.

Jetzt bestellen:

https://mohrsiebeck.com/buch/das-uebereinkommen-der-vereinten-nationen-ueber-die-verwendung-elektronischermitteilungen-bei-internationalen-vertraegen-9783161513978?no_cache=1

order@mohrsiebeck.com

Telefon: +49 (0)7071-923-17

Telefax: +49 (0)7071-51104 